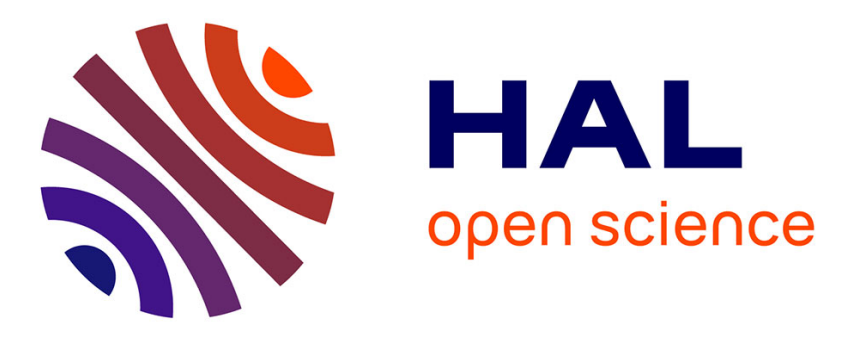

\title{
Passivation process of high Tc superconductors YBa2Cu3O7-d by fluorine gas treatment
}

\author{
A. Tressaud, Bernard Chevalier, B. Lépine, Jean-Michel Dance, Lucien \\ Lozano, Jean Grannec, Jean Etourneau, Robert Tournier, André Sulpice, \\ Pascal Lejay
}

\section{To cite this version:}

A. Tressaud, Bernard Chevalier, B. Lépine, Jean-Michel Dance, Lucien Lozano, et al.. Passivation process of high Tc superconductors $\mathrm{YBa} 2 \mathrm{Cu} 3 \mathrm{O} 7-\mathrm{d}$ by fluorine gas treatment. Modern Physics Letters B, 1988, 02 (10), pp.1183-1188. 10.1142/S0217984988001119 . hal-02950163

\section{HAL Id: hal-02950163 https://hal.science/hal-02950163}

Submitted on 29 Oct 2021

HAL is a multi-disciplinary open access archive for the deposit and dissemination of scientific research documents, whether they are published or not. The documents may come from teaching and research institutions in France or abroad, or from public or private research centers.
L'archive ouverte pluridisciplinaire HAL, est destinée au dépôt et à la diffusion de documents scientifiques de niveau recherche, publiés ou non, émanant des établissements d'enseignement et de recherche français ou étrangers, des laboratoires publics ou privés. 


\title{
PASSIVATION PROCESS OF HIGH $T_{c}$ SUPERCONDUCTORS $\mathrm{YBa}_{2} \mathrm{Cu}_{3} \mathrm{O}_{7-\delta}$ BY FLUORINE GAS TREATMENT
}

\author{
A. TRESSAUD, B. CHEVALIER, B. LEPINE, J. M. DANCE, L. LOZANO, \\ J. GRANNEC and J. ETOURNEAU \\ Laboratoire de Chimie du Solide du CNRS, Université de BORDEAUX I, 351, cours de la \\ Libération, 33405 TALENCE, Cedex, France \\ R. TOURNIER, A. SULPICE and P. LEJAY \\ Centre de Recherche sur les Très Basses Températures, CNRS - BP $166 \mathrm{X}-38042$ Grenoble, \\ Cedex, France
}

\begin{abstract}
The atmospheric degradation of high $T_{\mathrm{c}}$ superconductors $\mathrm{YBa}_{2} \mathrm{Cu}_{3} \mathrm{O}_{7-\delta}$ can be prevented using fluorine gas processings around room temperature. A thin layer of amorphous fluorides (and/or oxyfluorides) is formed at the surface of the particles, which passivates the material against hydrolysis and gas-exchange processes. A fluorination mechanism has been proposed, which can account for both fluorine analysis and weight uptake. The superconductivity onset does not seem to be affected by fluorination. Furthermore, an improvement of the shielding effect-Meissner effect cycle to $91 \%$ reversibility is achieved when $F_{2}$-treated oxides are heated at $350^{\circ} \mathrm{C}$ under vacuum.
\end{abstract}

\section{Introduction}

The discovery of high temperature superconductivity in $\mathrm{YBa}_{2} \mathrm{Cu}_{3} \mathrm{O}_{7-\delta}$ oxides has led to intensive activities in the synthesis of new attractive compounds and in the search of technological improvements.

Concerning the potential use of these materials, one of the main drawbacks is their great reactivity vs various reagents. Several researchers have pointed out that major degradation of $\mathrm{YBa}_{2} \mathrm{Cu}_{3} \mathrm{O}_{7-\delta}$ oxides occurs in moist air. ${ }^{1,2}$ The hydrolysis partly decomposes the oxide and yields $\mathrm{Ba}(\mathrm{OH})_{2}$ and $\mathrm{Y}(\mathrm{OH})_{3}$ hydroxydes and $\mathrm{CuO}$ oxide. In a second step, atmospheric $\mathrm{CO}_{2}$ reacts with $\mathrm{Ba}(\mathrm{OH})_{2}$ to give rise to $\mathrm{BaCO}_{3}$. These mechanisms considerably deteriorate the superconducting characteristics of the ceramics.

The use of these oxides in devices such as Josephson junctions is therefore subject to an efficient protection of the materials against ambient moisture and gas exchange processes.

We have been currently investigating the influence of fluorination on the superconducting properties of $\mathrm{YBa}_{2} \mathrm{Cu}_{3} \mathrm{O}_{7-\delta}$. The occurrence of a passivating layer of amorphous fluoride (and/or oxyfluoride) has been confirmed by various 
physical techniques: X-ray diffraction, ESR, Auger spectroscopy, magnetic and conductivity measurements. ${ }^{3}$

In the present work, we report the passivation of $\mathrm{YBa}_{2} \mathrm{Cu}_{3} \mathrm{O}_{7-\delta}$ oxides using a fluorine gas treatment around room temperature.

\section{Experimental}

$\mathrm{YBa}_{2} \mathrm{Cu}_{3} \mathrm{O}_{7-\delta}$ was prepared by thermal treatment of stoichiometric mixtures of $\mathrm{BaCO}_{3}, \mathrm{Y}_{2} \mathrm{O}_{3}$ and $\mathrm{CuO}$. After a $12 \mathrm{hr}$ heating cycle at $900^{\circ} \mathrm{C}$ in air, the resulting product was ground and treated again in the same conditions for $24 \mathrm{hr}$. An annealing at $500^{\circ} \mathrm{C}$ was performed either in air or in oxygen atmosphere during $24 \mathrm{hr}$, which was followed by a cooling at $100^{\circ} \mathrm{C} / \mathrm{hr}$ rate.

The oxide has been proved to exhibit an orthorhombic symmetry, with unitcell constants $a=3.824 \AA, b=3.890 \AA, c=11.72 \AA$ in good agreement with those published previously. ${ }^{4}$

Fluorine gas treatments were carried out in a "fluorination line" using handling procedures described elsewhere. ${ }^{5}$ The oxide was set as pellets in a nickel boat. The nickel reaction tube was filled with one atmosphere of pure $F_{2}$ gas. The product was kept under a moderate flow of fluorine for $5 \mathrm{hr}$ and allowed to stand overnight under 1.3 bar $F_{2}$ atmosphere. When the materials were fluorinated at low temperature $\left(T \leqslant 100^{\circ} \mathrm{C}\right)$ no change in color, nor weight uptake larger than $1 \%$ were noticed. No further weight increase was observed even when the pellets were kept for 20 days at room temperature under 1.3 bar $F_{2}$ atmosphere.

The materials were characterized before and after fluorination using $\mathrm{X}$-ray diffraction (Cu- $\mathrm{K}_{\alpha}$ ), Auger electron spectroscopy (AES) and electron microprobe techniques. Elemental analyses were carried out at Service Central d'Analyses du CNRS. The temperature dependence of the magnetization was measured at GRENOBLE using a SQUID magnetometer.

\section{Results and Discussion}

Figure 1 showed $\mathrm{X}$-ray patterns of $\mathrm{YBa}_{2} \mathrm{Cu}_{3} \mathrm{O}_{7-\delta}$ (a) freshly prepared, (b) after a 4 months exposure to room atmosphere. In the latter spectrum, new peaks can be noted, which are due to the occurrence of baryum carbonate. When the oxide of (a) is previously $F_{2}$-treated at $20^{\circ} \mathrm{C}$, no change occurs in the X-ray pattern, even when the sample is kept in moist air for long periods (up to 4 months) (c).

For non-treated samples, the observed hydrolysis process appears to be in good agreement with the results of Zhuang Dexin et al. ${ }^{1}$

In order to know whether fluorine has been incorporated during the reaction, an AES study of the surface of a ceramic material has been carried out. Figure 2 shows concentration profiles of carbon, oxygen and fluorine in $\mathrm{YBa}_{2} \mathrm{Cu}_{3} \mathrm{O}_{7-\delta}$ (a) before and (b) after the $\mathrm{F}_{2}$ treatment. Fluorine and oxygen are both present at the surface of the fluorinated sample and noticeable amounts of fluorine can be 


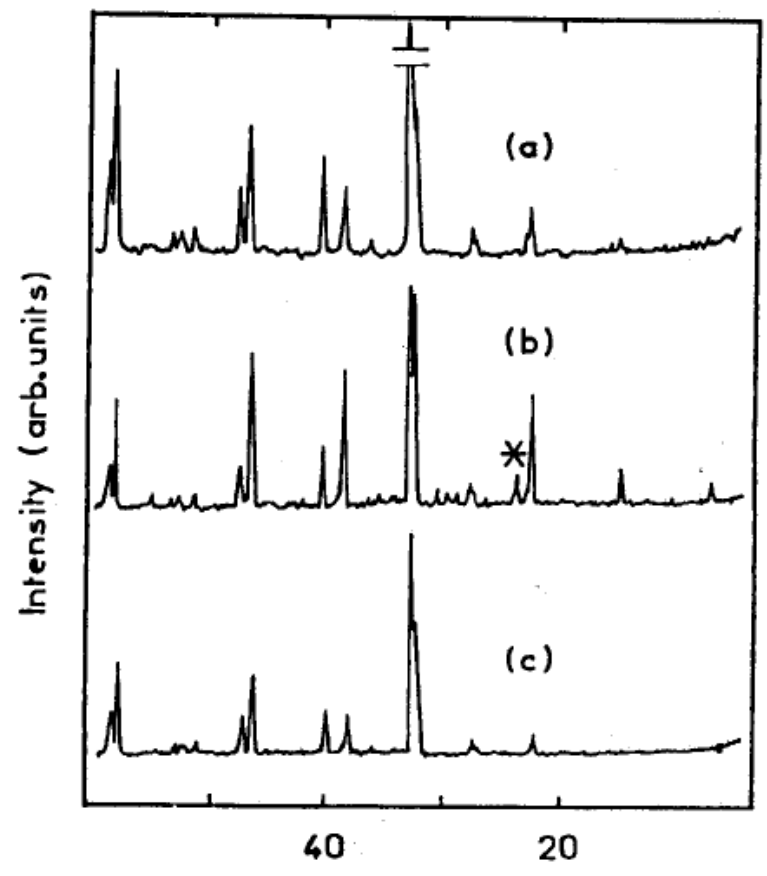

Angle (20)

Fig. 1. Part of the X-ray powder spectra of $\mathrm{YBa}_{2} \mathrm{Cu}_{3} \mathrm{O}_{7-\delta}$ : (a) freshly prepared, (b) exposed to the atmospheric moisture for 4 months (*indicates the $\mathrm{BaCO}_{3}$ diffraction peak), (c) treated in fluorine gas at $20^{\circ} \mathrm{C}$ and exposed in atmospheric moisture for 4 months.

observed to 200-300 A deep from the surface. The monotonic decrease of $F$ content and the absence of a plateau with constant $F / O$ ratio tend to confirm the absence of any stoichiometric oxyfluoride at the surface. This study shows that the $F_{2}$ process affects only the surface of the particles. Furthermore, the presence of carbon, which indicates in the case of the pristine oxide the occurrence of carbonate, seems to be totally inhibited in $\mathrm{F}_{2}$ treated samples.

$\mathrm{O}$ and $\mathrm{F}$ analyses carried out on a series of ceramics which had been vacuum treated prior to $\mathrm{a}_{2}$-treatment at $20^{\circ} \mathrm{C}$ are given below [the weight uptake during the fluorination is $\Delta m=+0.7 \%$ ]:

- before $F_{2}$ treatment: 6.7 oxygen atmosphere mole,

- after $F_{2}$ treatment: 0.45 fluorine atom and 6.3 oxygen atoms (by difference) per mole.

Using the assumption that the fluorination mechanism yields amorphous fluorides of bulk composition " $\mathrm{YBa}_{2} \mathrm{Cu}_{3} \mathrm{~F}_{13}$ " with a subsequent oxygen departure, the amount of oxide moles which has been involved in the decomposition process can be calculated from either fluorine analysis or from weight uptake: a value of $3.3 \%$ can account for both results. 


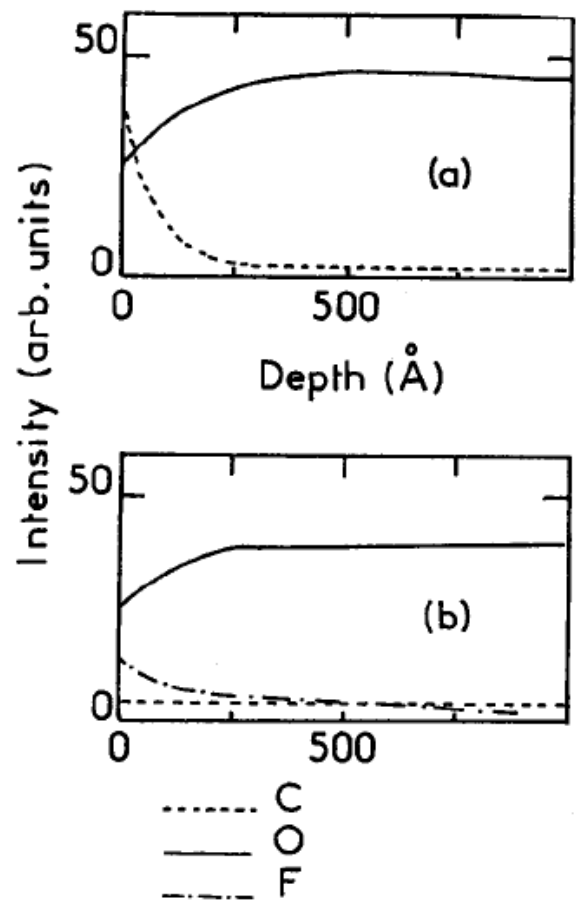

Fig. 2. Concentration profiles of carbon, oxygen and fluorine in $\mathrm{YBa}_{2} \mathrm{Cu}_{3} \mathrm{O}_{7-\delta}$ (a) before and (b) after the fluorine gas treatment at $20^{\circ} \mathrm{C}$.

It can be anticipated that the passivation layers obtained at low temperature are amorphous since complete fluorinations of powdered $\mathrm{YBa}_{2} \mathrm{Cu}_{3} \mathrm{O}_{7-\delta}$ samples, which occur even below $200^{\circ} \mathrm{C}$, do not yield crystallized materials. ${ }^{3}$

Low temperature $F_{2}$ gas treatment have almost no influence on the superconductivity onset of the starting materials. Figure $3 \mathrm{a}$ shows the thermal variation of the magnetization below $T_{\mathrm{c}}$ in an applied field of $10 \mathrm{Oe}$ for $\mathrm{YBa}_{2} \mathrm{Cu}_{3} \mathrm{O}_{7-\delta}$ before and after a $\mathrm{F}_{2}$ treatment at $20^{\circ} \mathrm{C}$. The measurements have been done after a zerofield cooling of the sample (shielding effect) or under an applied field (Meissner effect).

Fluorination treatment does not affect the superconducting volume significantly as can be seen from Fig. 3a, in which the magnetization curves of the materials before and after treatment can be practically superimposed.

When $\mathrm{YBa}_{2} \mathrm{Cu}_{3} \mathrm{O}_{7-\delta}$ oxides are treated under vacuum, it is well known that the oxygen content is lowered and that a complete disappearance of the superconductivity can even be observed. ${ }^{4}$ This behavior is obtained for instance when the starting oxide is heated for $2 \mathrm{hr}$ at $500^{\circ} \mathrm{C}$ in secondary vacuum: the superconductivity vanishes completely. On the other hand when the product has been $F_{2}$-treated previously, an identical processing does not destroy the superconductivity completely, in spite of considerable lowering of both $T_{c}$ and 


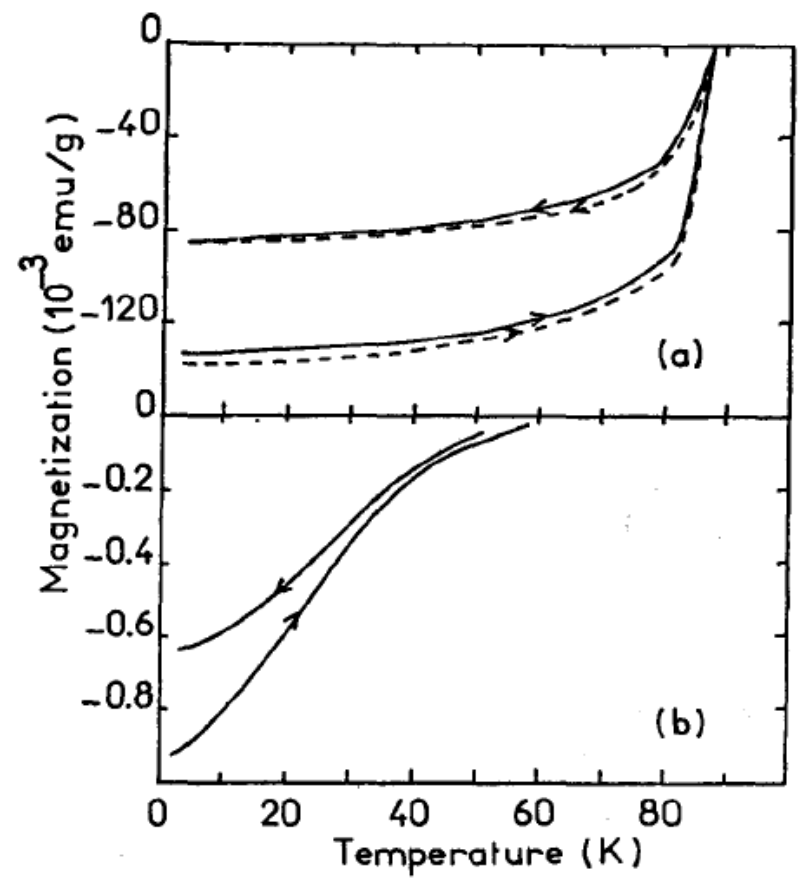

Fig. 3. Magnetization of $\mathrm{YBa}_{2} \mathrm{Cu}_{3} \mathrm{O}_{7-\delta}$ as a function of temperature in an applied field $\mathrm{H}=10 \mathrm{Oe}$ before (-) and after (-) the fluorine gas treatment at $20^{\circ} \mathrm{C} \mathrm{(a)}$ and after the vacuum annealing at $500^{\circ} \mathrm{C}(\mathrm{b})$.

diamagnetic signal (Fig. 3b). This result shows that the fluoride layer inhibits the evolution of oxygen during vacuum treatments.

The thermal variation of another $F_{2}$-treated oxide sample is shown in Fig. 4. At $10 \mathrm{~K}$ the ratio: Meissner effect to shielding effect is of $61 \%$. This non reversible property of the diamagnetic signal is well known for this type of oxides and can be

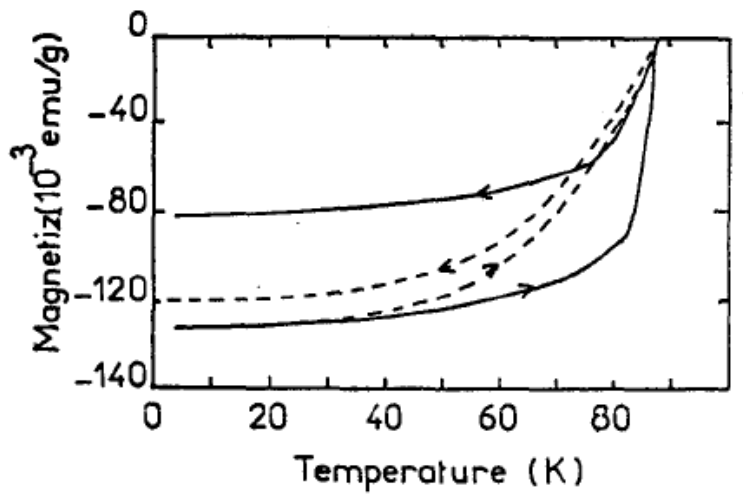

Fig. 4. Magnetization vs temperature for $\mathrm{YBa}_{2} \mathrm{Cu}_{3} \mathrm{O}_{7-\delta}$ treated in a fluorine gas atmosphere before $(-)$ and after (-) the vacuum annealing at $350^{\circ} \mathrm{C}$. 
correlated to inhomogeneities: structural defects at the surface can induce an important pinning of the vortex. After a $4 \mathrm{hr}$ annealing at $350^{\circ} \mathrm{C}$ under secondary vacuum, the $F_{2}$-treated oxide still has a superconductivity onset at $89 \mathrm{~K}$ but it exhibits a quasi-reversibility of the cycle shielding effect-Meissner effect (Fig. 4). At $10 \mathrm{~K}$, the ratio reaches $91 \%$. It seems clear once more that the fluoride layer treated under appropriate thermal conditions eliminates the surface inhomogeneities of this superconductor.

\section{Conclusions}

When $\mathrm{YBa}_{2} \mathrm{Cu}_{3} \mathrm{O}_{7-\delta}$ oxides are treated in a fluorine-gas atmosphere at low temperature, the degradation of the material in moist air is prevented. This curing process can be ascribed to the formation of a layer of amorphous fluoride at the surface of the particles, which passivates the material against hydrolysis. Even after vacuum processing at $500^{\circ} \mathrm{C}$, the "fluorinated" oxide still exhibits some superconductivity. An identical procedure carried out at $350^{\circ} \mathrm{C}$ preserves the superconductivity of the material and improves, moreover, the shielding effect-Meissner effect cycle towards an almost reversibility.

\section{Acknowledgment}

This work has been carried out with the support of Rhône-Poulenc Co.

\section{References}

1. Zhuang Dexin, Xiao Mingshan, Zhang Ziqing, Yue Shubin, Zhao Huansui and Shang Shuxia, Solid State Commun. 65 (1988) 339.

2. J. G. Thompson, B. G. Hyde, R. L. Withers, J. S. Anderson, J. D. Fitz Gerald, J. Bitmead, M. S. Paterson and A. M. Stewart, Mat. Res. Bull. 22 (1987) 1715.

3. A. Tressaud, B. Chevalier, B. Lépine, J. M. Dance, L. Lozano, K. Amine, J. Etourneau, R. Tournier, A. Sulpice, P. Lejay, J. L. Diot and P. Maestro, J. Phys. (to be published).

4. J. M. Tarascon, W. R. McKinnon, L. H. Greene, G. W. Hull and E. M. Vogel, Phys. Rev. B 36 (1987) 226.

5. J. Grannec and L. Lozano, in "Inorganic Solid Fluorides" ed. P. Hagenmuller (Academic Press, New York), Chap. 2 (1985) 17. 